\title{
Tool wear predictability estimation in milling based on multi-sensorial data
}

\author{
P. Stavropoulos ${ }^{1,2}$ - A. Papacharalampopoulos ${ }^{1}$ - E. Vasiliadis $^{1}$ - G. Chryssolouris ${ }^{1}$
}

Received: 20 October 2014 / Accepted: 13 May 2015 /Published online: 14 June 2015

(C) The Author(s) 2015. This article is published with open access at Springerlink.com

\begin{abstract}
The safe and reliable operations in industrial manufacturing processes play a crucial role in the economic productivity. Machining process disturbances such as collision, overload, breakdown, and tool wear tend to cause production system failures. The current study aims at investigating the limitations of tool wear prediction on the milling of CGI 450 plates, through the simultaneous detection of acceleration and spindle drive current sensor signals. Tool wear prediction has been accomplished, by utilizing the experimental results that derived from third degree regression models and pattern recognition systems. These results indicate that predictability is affected by the mean signal energy, acquired from the vibration acceleration signals.
\end{abstract}

Keywords Tool wear $\cdot$ Monitoring $\cdot$ Predictability $\cdot$ Fused sensorial signals $\cdot$ Pattern recognition

\section{Introduction}

The milling process that belongs in the category of mechanical material removal processes forms the backbone of industrial manufacturing practices, by providing great flexibility, since the shape and the kinematics of the tool and workpiece define the parts' geometry [1]. A milling cutter's design and its

G. Chryssolouris

xrisol@mech.upatras.gr

1 Laboratory for Manufacturing Systems and Automation, Department of Mechanical Engineering and Aeronautics, University of Patras, Patras 265 00, Greece

2 Department of Aeronautical Studies, Hellenic Air Force Academy, Dekelia Air-Force Base, TGA 1010 Athens, Greece respective cutting edges come in a vast range of shapes and sizes [2]. The current practice in industrial environments implies the usage of trial and error techniques for the very first machined parts so as to evaluate and fine tune the machining process. This approach not only does it require a significant amount of time, but potentially, it also contains a significant number of errors, thus reducing the performance of the process in terms of profit, people, and pollution [3]. A major issue is the occurrence of tool wear. There is significant theoretical study $[1,4,5]$, and there is a background comprising literature that deals with corresponding sensing, processing methods [6], and reliability assessment [7]. This is due to the fact that successful monitoring [1] of the tool wear during machining may provide significant benefits in terms of cost and machining quality [8]. It is reported [9] that using wear sensors, a tool cost saving up to $40 \%$ may be reached. Thus, the trend is that the tool status be identified in terms of tool wear level via online sensing methods. The optimal goal is that this information be finally incorporated into the machining policy design and process planning. The first step to do that is to adopt a monitoring strategy, using available and suitable sensors. Concerning a primary classification of related sensors, they are divided into direct and indirect [10], depending on their relation to the phenomenon studied. The most frequently implemented monitoring systems involve in-direct sensors [11]. In these types of systems, auxiliary quantities which are affected by tool wear are measured. These quantities have been empirically correlated with those deriving from machining phenomena [12].

Sensors and sensing devices, such as torque [13], acoustic emission [14], or even feed rate [15], are classified in detail into [6]. As regards milling operations, numerous studies have proven the link between tool condition monitoring and various indirectly linked quantities/measures. The effectiveness of acoustic emissions (AE), excited by machining-related 
mechanical phenomena has been documented in [16-18]. However, they are primarily used in detecting tool breakage and not wear, due to the fact that the breakage phenomenon causes an eminent peak in the AE signal [19-21]. In the same framework of mechanical vibration sensing, surface roughness measurements [22] and cutting forces [23-25] (or eddy currents [26]) have been utilized. Cutting force signals may be affected by the dynamic behavior of the machine [27] or limit the machining envelope [28-30]. Spindle motor current is another factor, affected by the cutting force, and it has also been used in tool condition monitoring. The implementation of signal filtering to minimize the machine noise increases the stability of such systems' performance. Between spindle current consumption and cutting force monitoring, the tool wear level identification is accomplished [31]. Such an approach is characterized as having a low cost when compared to that of conventional monitoring methods. Trends of the last two decades, in the field of machining monitoring, highlight the effectiveness of techniques, based on the signal acquisition of different types of sensors, also known as sensor fusion [29]. This kind of systems provides effective and efficient integration with information sourcing from different sensors of different nature to achieve an integrated description of the tool's status while machining [32-37]. A major drawback of these methods is that they usually require a great amount of data. Study [38] indicates that less costly and mountable current and voltage sensors may offer an alternative to force sensors for industrial tool condition monitoring. As regards the methods of acquired signal processing, an evaluation of approaches was originally presented in [24]. It is apparent that in order for an accurate interpretation of the information produced to be provided, a high level of signal processing and analysis is required. The simplest method is through the use of a constant threshold. If the latter is crossed tool wear or tool breakage can be detected. The use of a dynamic threshold is considered being a more reliable approach to various case studies [27]. Numerous domains such as the time domain [39], the spectrum [39], and the hybrid [40] have been utilized so far throughout the literature along with reviews. There are also statistical processing [41], pattern recognition methods [42], or even semi-empirical methods, such as autoregressive models [43]. Even more sophisticated methods of processing and decision making involve the hidden Markov models, ANFIS [44], fractal characterization [45], or support vector machines [46]. Besides, there are numerous works [41, 45, 13] that correlate the tool wear with various parameters (such as RPMs and feed rate).

Part of the current study in the FoFdation project [47] is based, among others, on achieving the creation of a tool offering a realistic adaptive approach that compensates for the condition changes, during the milling process. Tool wear prediction is a functionality aiming at preventing a catastrophic behavior. Correlation between the cutting force and the tool wear has proven sufficient and it has been utilized as a means of tool wear prediction. Replicating the same machining conditions, in overlap [48] and in mixing up and down milling [49], in case of a different machine tool, additional studies have also correlated tool wear with electrical current [31]. The missing link (mechanism) between the investigations is the cutting force. In the current study, the first set of studies following, aims to investigate into the type of components of raw vibration and/or electrical signals that carry tool-wearrelated information.

A multiple sensor system for the monitoring of milling operations has been developed for the current investigation. The objective is that tool wear be correlated with spindle torque and the accelerometer signals. The choice of the sensors has been made under the prism of low cost and easiness to integrate in real industrial environments. The strategy of the wear experiments, including process parameters and machining motion profile, has been designed so to allow the incorporation of statistical parameters that may alter the prediction relationship. Such parameters may be: the cutting force variations, the statistical behaviour of the vibrations and the relationship between spindle current and cutting force. The predictions have also been correlated with the machine tool dynamic behaviour, as it is proven that they have a close relationship [14, 32]. The machine tool behaviour affects the cutting forces, which are used for the monitoring of tool wear [15] and thus affect the tool wear predictability. To this end, from the signal's processing point of view, a regression model has been developed for the estimation of tool wear, based on experimental data, and the pattern recognition systems used, for both single and fused sensors' data processing. A correlation has also been implemented with machine tool dynamics, aiming to study the system's predictability. Metrics have been applied to measure the predictability and study the tool wear prediction.

\section{Experimental setup}

\subsection{Material and equipment}

The CGI 450 was the material used in the tool wear machining experiments [50]. For the current set of experimental investigation, the workpiece dimensions have been selected to be equal to $250 \mathrm{~mm} \times 250 \mathrm{~mm} \times 50 \mathrm{~mm}$. Placement and fixturing of the CGI plates on the mill bed have been as indicated in Fig. 1. Material properties and chemical composition are shown in Tables 1 and 2, respectively.

The cutting tool used in the current experimental investigation is SANDVIK 365 face milling with 5 PVD titanium nitride coated carbide inserts, namely the N365-1505ZNEKW4 1020. Its tool diameter is equal to $50 \mathrm{~mm}$. The cutting tool's selection is aligned with the standards of the same type 


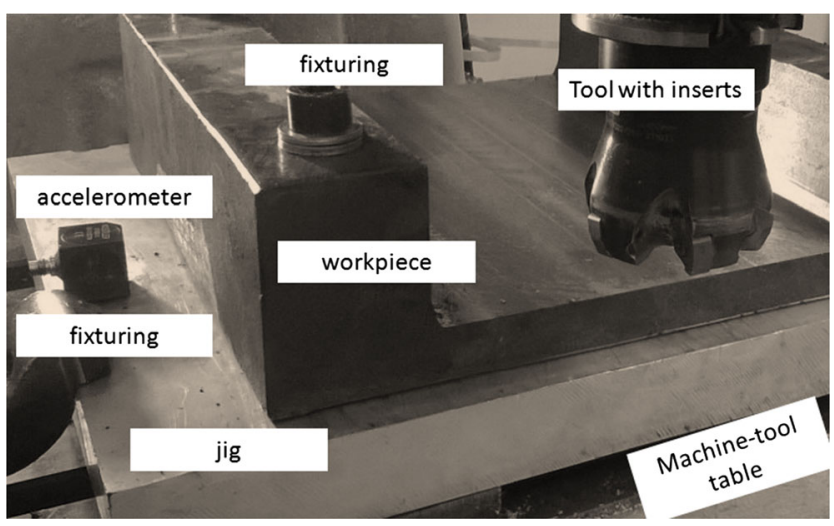

Fig. 1 Experimental setup and accelerometer mounting

of industrial applications in terms of average cutting speeds $[50,51]$. Finally, the machine tool used is an XYZ three-axis vertical milling machine with a Prototrak controller and a 5 HP spindle type.

\subsection{Monitoring equipment}

A PC-based data acquisition system (Fig. 2) has been used, consisting of an eight-channel dynamic signal acquisition module and a dedicated analog-to-digital converter per channel. The acceleration sensor was a triaxial accelerometer with an effective frequency range, up to $7 \mathrm{kHz}$, and a sensitivity of $100 \mathrm{mV} / \mathrm{g}$. The current measurement has been performed via a power analyzer and inductive clamps. There was a special jig (Fig. 1) for mounting of the accelerometer as closely as possible to the machining area.

\subsection{Experimental procedure}

As per the findings of previous studies [31, 47-49], the tool path during machining is shown in Fig. 3, with the feed direction during cutting along the $y$-axis. Each pass consists of six passages, and the cutting path of the tool is denoted with a dashed line. Dotted parts in Fig. 3 schematic indicate no cutting regions. The axial depth of cut has been set to $0.5 \mathrm{~mm}$ with the width of cut equal to $50 \%$ of the tool diameter $(25 \mathrm{~mm})$. Cutting conditions have been selected for the upper operating region of the tools aiming at the acceleration of tool

Table 1 Material mechanical properties

Table 2 Material chemical composition

\begin{tabular}{ll} 
CGI 450 chemical composition \\
\hline Pearlite & $>90$ \\
$\mathrm{C}$ & $3.6-3.8$ \\
$\mathrm{SI}$ & $2.1-2.5$ \\
$\mathrm{CE}$ & $4.4-4.7$ \\
$\mathrm{Mn}$ & $0.2-0.4$ \\
$\mathrm{~S}$ & $<0.022$ \\
$\mathrm{Mg}$ & $<0.014$ \\
$\mathrm{CeMM}$ & $0.01-0.03$ \\
$\mathrm{Cu}$ & $0.7-1.0$ \\
$\mathrm{Sn}$ & $0.08-0.10$ \\
\hline
\end{tabular}

Source: Doukas et al. [31]

wear progression. The feed per tooth has been constant (equal to $0.15 \mathrm{~mm}$ ) in all cases, while the cutting speed varied as indicated in Table 3. Three values of the spindle rotational velocity have been selected, namely 1350,2175 , and 3000 RPMs, resulting in cutting speeds equal to 210,338 , and $467 \mathrm{~m} / \mathrm{min}$ respectively. The feed rate has been equal to $1000 \mathrm{~mm} / \mathrm{min}$, while the depth of cut was equal to $0.5 \mathrm{~mm}$. Targeting tool wear, dry cutting conditions have been selected.

The experiment consisted of machining straight lines with cutting parameters as described above. Following a predefined time period, the process had been paused in order for the inserts to be changed. The accelerometer signals and spindle current have been monitored during each pass for 5-s intervals. The tool wear level has been assessed by optical microscopy measurements for each full set of inserts.

\section{Results}

\subsection{Microscope photos}

Worn inserts have been removed from the tool and examined under a camera, equipped with an optical microscope. A reference mark has been added to each picture for measurement purposes. Figure 4 shows a microscopy photo of the flank and crater wear. For the purposes of the study, a mean value has been calculated out of five values of each experimental run, one for each insert.

\subsection{Tool wear levels and Taylor curves}

CGI 450 mechanical properties

\begin{tabular}{ll}
\hline Ultimate tens. strength & $450-500 \mathrm{MPa}$ \\
Yield strength & $315-365 \mathrm{MPa}$ \\
Elastic modulus & $145-155 \mathrm{GPa}$ \\
Density & $7-7.2 \mathrm{gn}$ \\
Hardness & $207-255 \mathrm{BHN}$ \\
\hline
\end{tabular}

Source: Doukas et al. [31]
Figures 5, 6, and 7 indicate the progression of the mean flank wear $[\mu \mathrm{m}]$ over machining time for the three levels of RPMs, as indicated in Table 3. Taking into account the final measurement of each diagram, the mean tool wear rate can be approximately estimated at $120 / 660=0.18,126 / 660=0.19$, and 180 / $826=0.22 \mu \mathrm{m} / \mathrm{s}$, for increasing values of RPMs, which is in accordance with the tool wear theory and Taylor's model [52]. 
Fig. 2 Monitoring system schematic

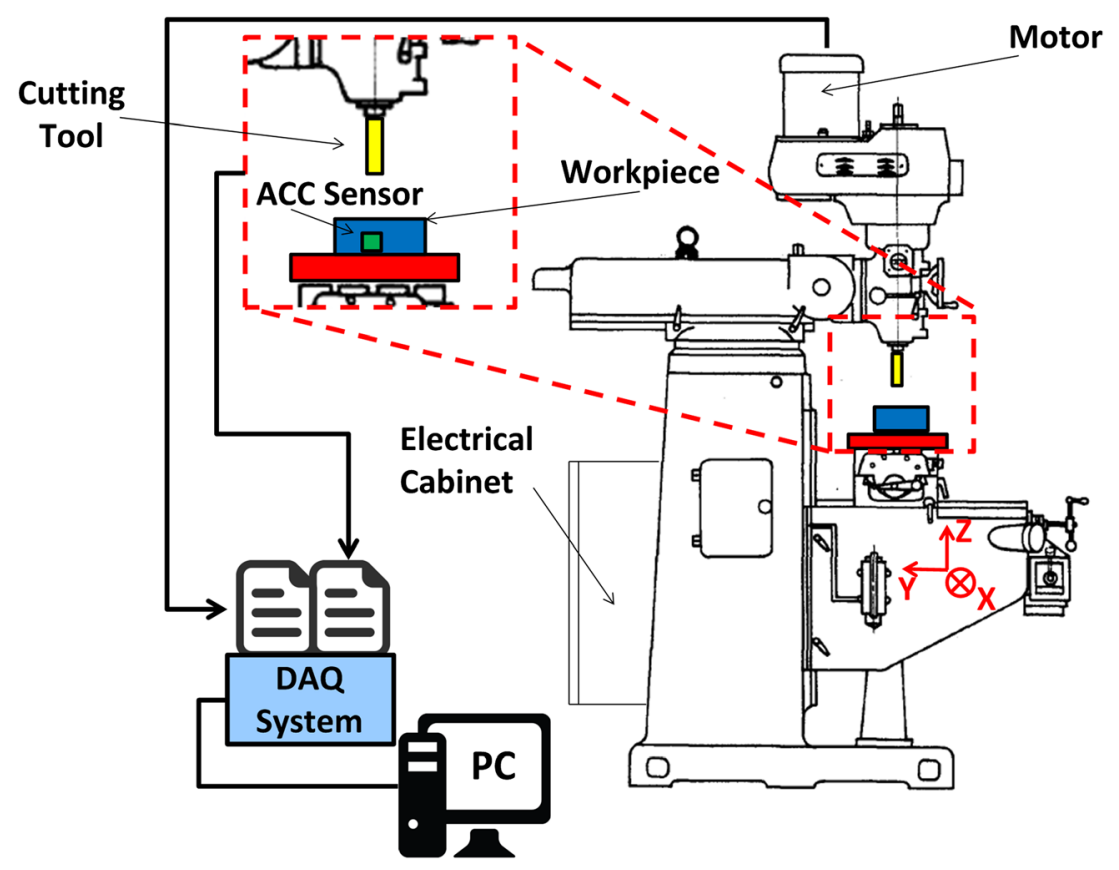

\subsection{Spindle current measurements}

The corresponding spindle electrical current measurements are shown in Figs. 8, 9, and 10, for various cutting speeds according to the experimental data (Table 3). Each curve corresponds to a single experiment with a variation number of passes. The measurements indicate an increasing trend, implying that there is a correlation between the tool wear level and the spindle current signals.

\subsection{Accelerometer measurements}

As indicated in [31], the high over low frequency band (HoL) index, based on a primary filter bank analysis and the mean
Fig. 3 Machining strategy schematic

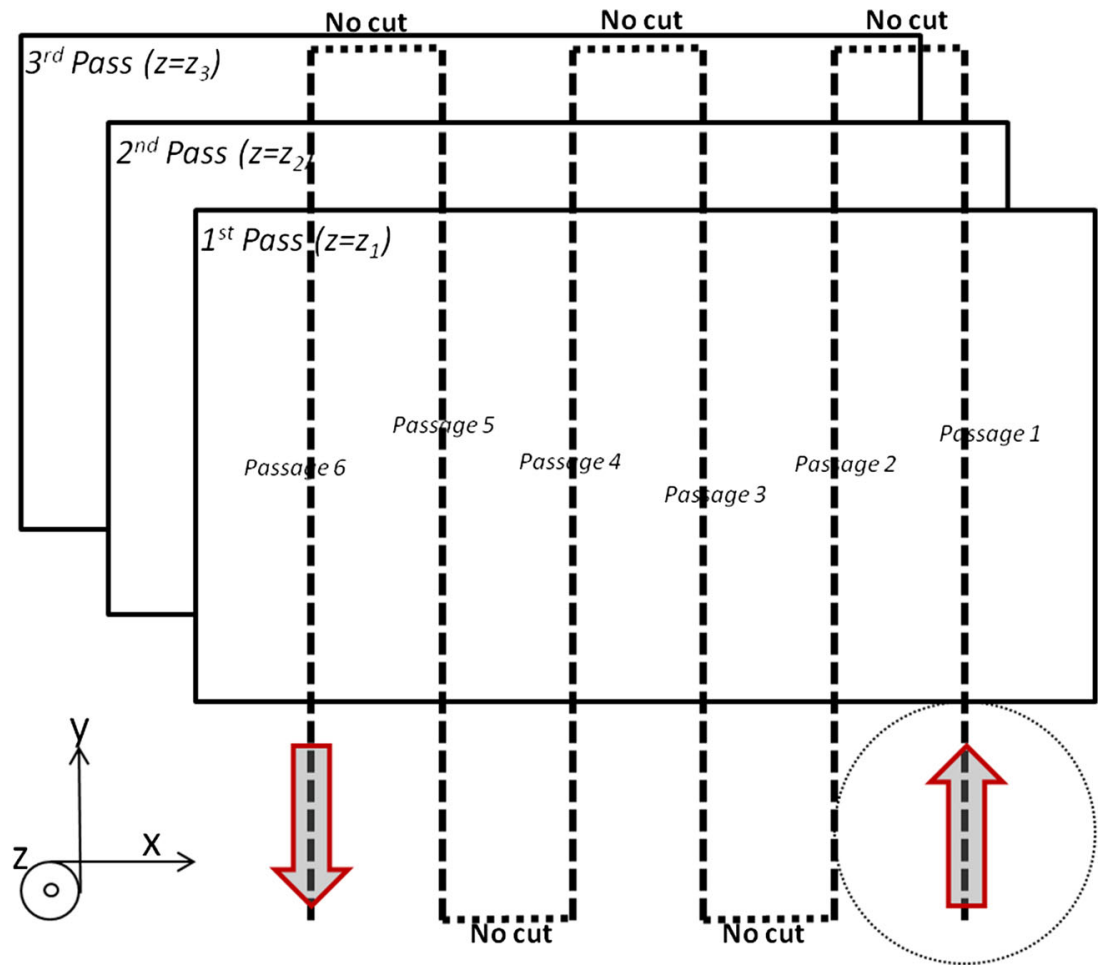


Table 3 Experiments data

\begin{tabular}{|c|c|c|}
\hline \multicolumn{3}{|l|}{ Experimental plan } \\
\hline \multicolumn{3}{|l|}{ Depth of cut $=0.5 \mathrm{~mm}$} \\
\hline \multicolumn{3}{|l|}{ Width of cut $=25 \mathrm{~mm}$} \\
\hline \multicolumn{3}{|c|}{ Feed $/ \mathrm{z}=0.15 \mathrm{~mm}($ Feed rate $=1 \mathrm{~m} / \mathrm{min})$} \\
\hline Set 1 & Set 2 & Set 3 \\
\hline $\mathrm{V}_{\mathrm{f}}=210 \mathrm{~m} / \mathrm{min} 1350 \mathrm{rpm}$ & $\mathrm{V}_{\mathrm{f}}=340 \mathrm{~m} / \mathrm{min} 2175 \mathrm{rpm}$ & $\begin{array}{c}\mathrm{V}_{\mathrm{f}}=470 \mathrm{~m} / \mathrm{min} \\
3000 \mathrm{rpm}\end{array}$ \\
\hline
\end{tabular}

square of the acceleration, can be utilized. It is worth noting that the mean square of the acceleration is equal to the mean signal power, since the mean value of acceleration has been approximately equal to zero, which is predictable, considering that during monitoring, the accelerometer's motion is of constant velocity, due to constant feed rate value. The progress of the signal's spectrum magnitude is shown below for the case of 3000 RPMs (Fig. 11).

Since the distinction between the vibrations and the wave propagation can be made via a time scale [53], the detection of the tool wear level, using vibration signals, can be straightforward, especially at wavelengths comparable to the tool wear size $[53,54]$. Utilizing the $S$ wave velocity in nitride titanium [55] and the fact that the tool wear characteristic length, as measured, is about $100 \mu \mathrm{m}$, the frequency to be detected is in the range of $100 \mathrm{MHz}$. Technological limitations of instrumentation utilized in the current study (i.e., accelerometermaximum frequency acquired) do not allow the aforementioned. Thus, only indirect effects can be detected on the signals, occurring from the change in the vibrations, sourcing from the change of the cutting force. This fact implied that the signal noise was fed into the HoL-related model, in accordance with [31]. The RMS value of the electrical current signal could be used for the assessment of the wear level, while for the accelerometer signals, a frequency domain analysis seems to be the appropriate one for a useful indication of tool wear levels. The physical phenomena taking place are multifold and complex. However, partitions of the signal, even if

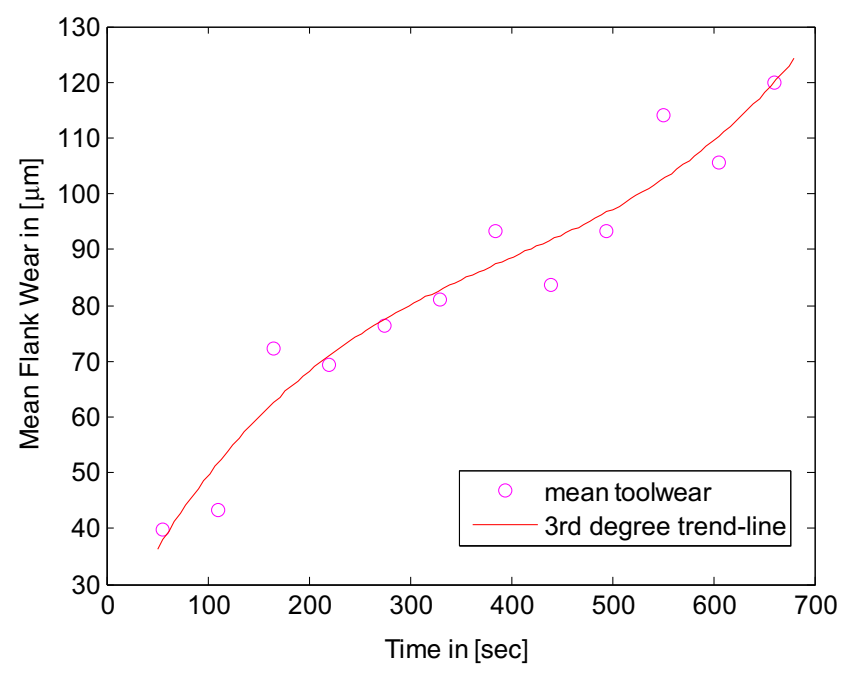

Fig. 5 Tool wear (flank) over time, at $1350 \mathrm{rpm}$

distorted due to the legacy system or ambient noise, may carry pieces of information correlated with tool wear. In the following sections, this prediction is studied and its limitations are attempted to be correlated with the form of the signal itself.

\section{Discussion of the results}

The aim of the current study is to identify and predict the wear state of the cutting tool. Two different methodologies are followed. Initially, empirical models were used, i.e., regression between the tool wear and the metrics derived from each one of the acquired signals individually (Figs. 12, 13, 14, 15, 16, 17, 18, and 19). As regards the spindle drive current, normalized RMS values have been used. On the other hand, acceleration has been taken into consideration in terms of HoL index. Finally, pattern recognition systems have been implemented using signals from one sensor (acceleration example hereafter in Fig. 20) and signals from both sensors (acceleration and electrical current in Fig. 23). The regression between the tool wear and the normalized spindle current, as well as the
Fig. 4 Microscopy photos showing the progress of the tool wear (a crater, b flank)
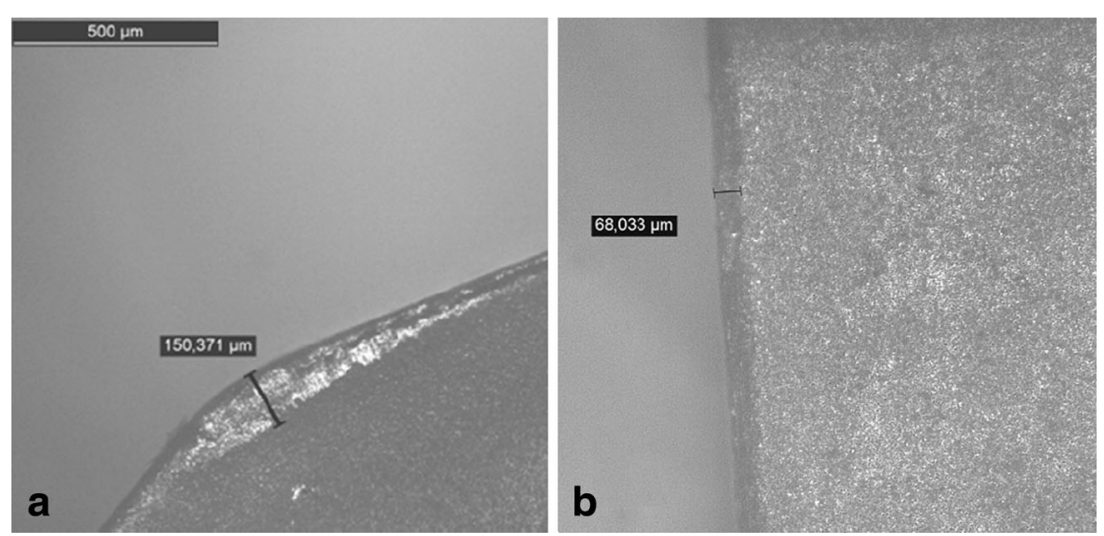


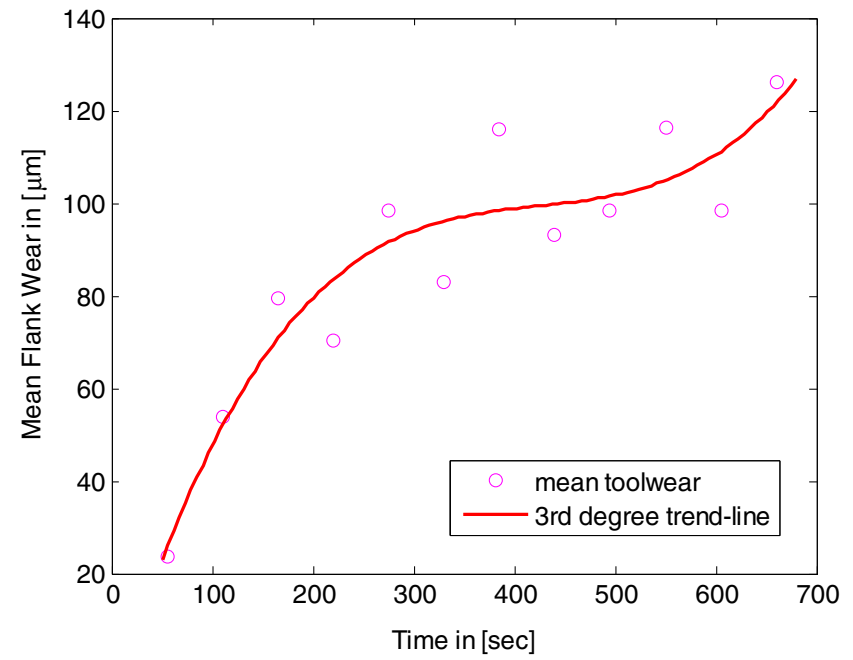

Fig. 6 Tool wear (flank) over time, at $2175 \mathrm{rpm}$

pattern recognition with the use of signals from both sensors, point out specific trends that can be used for the prediction of the tool wear. The diagrams below indicate the correlation between the normalized spindle current and the tool wear. All the trends, expressed by third degree polynomial regression, tend to be described by increasing functions. Increase in the RPMs tends to produce more clear wear trends. At high cutting speed values, the mean inclination tends to be positive all over the curve.

The following diagrams (Figs. 15, 16, and 17) correlate the forms of the curves acquired by correlating the tool wear-time and the tool wear-electrical current. It can be observed that, as the RPMs increase, the curves tend to follow identical paths. This has to do with the behavior of the electrical current; its time evolution becomes more linear in time as the RPMs increase.

As mentioned, the two curves (tool wear and spindle current) are clearly in harmony with each other in all three cases

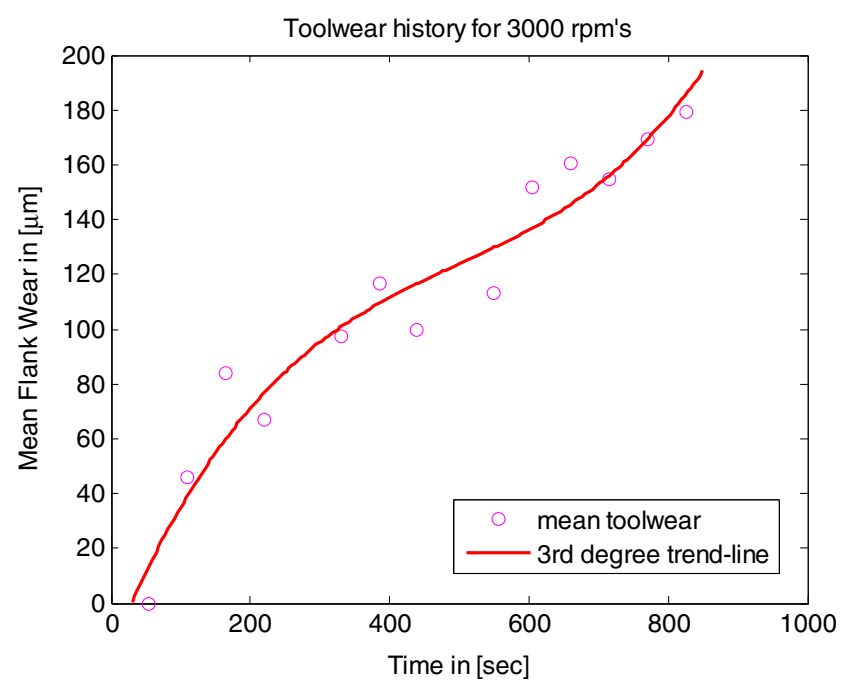

Fig. 7 Tool wear (flank) over time, at $3000 \mathrm{rpm}$

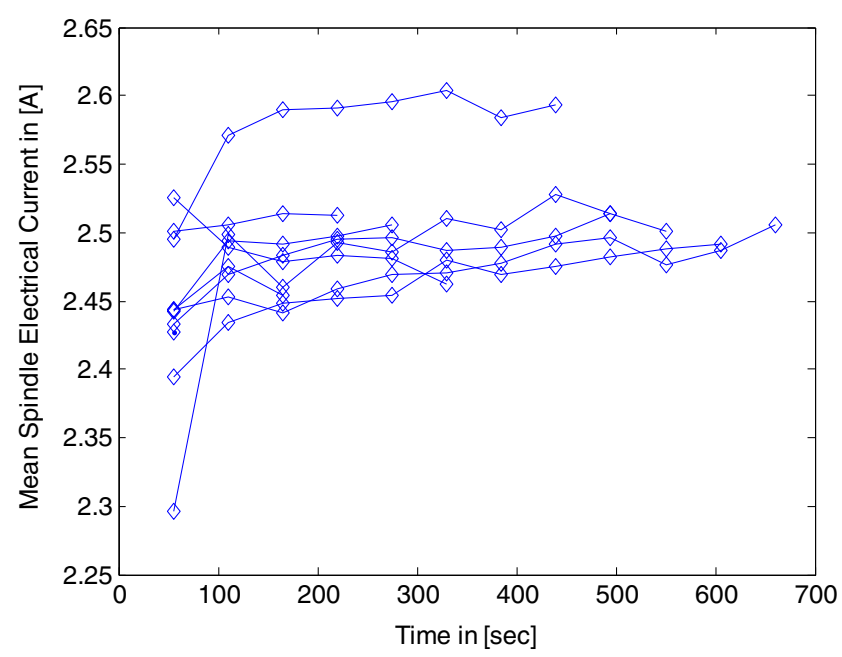

Fig. 8 Spindle current signals at $1350 \mathrm{rpm}$

(Figs 15, 16, and 17). However, in the case of 1350 RPM, the similarity between the two curves is not as apparent. This can be interpreted by the sampling strategy described in Sect. 2.3. The statistical nature of measurements in the present study (electrical current mean value from different experiments) seems to be affecting the efficiency of the tool wear prediction, especially for the high values of electrical current. This is due to the electrical current tendency in [31], where a noisy behavior is evident and a standard deviation of $0.05 \mathrm{~A}$ can be measured. This value interprets the uncertainty shown herein in Fig. 15. Finally, the fact that tool wear is regarded in terms of a mean value from five inserts, the uncertainty of $5 \mu \mathrm{m}$ can be explained.

Furthermore, the measurements of the acceleration HoL index are compared against the tool wear level. The index is designed to capture the redistribution of energy in frequencies, due to vibration changes caused by the increase in the tool wear level and consequently in the cutting force changes.

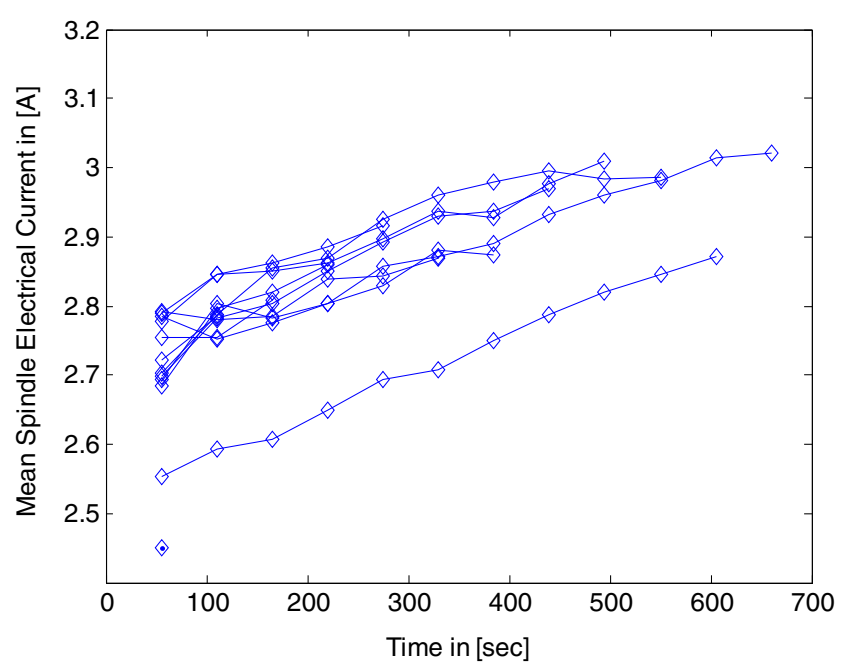

Fig. 9 Spindle current signals at $2175 \mathrm{rpm}$ 


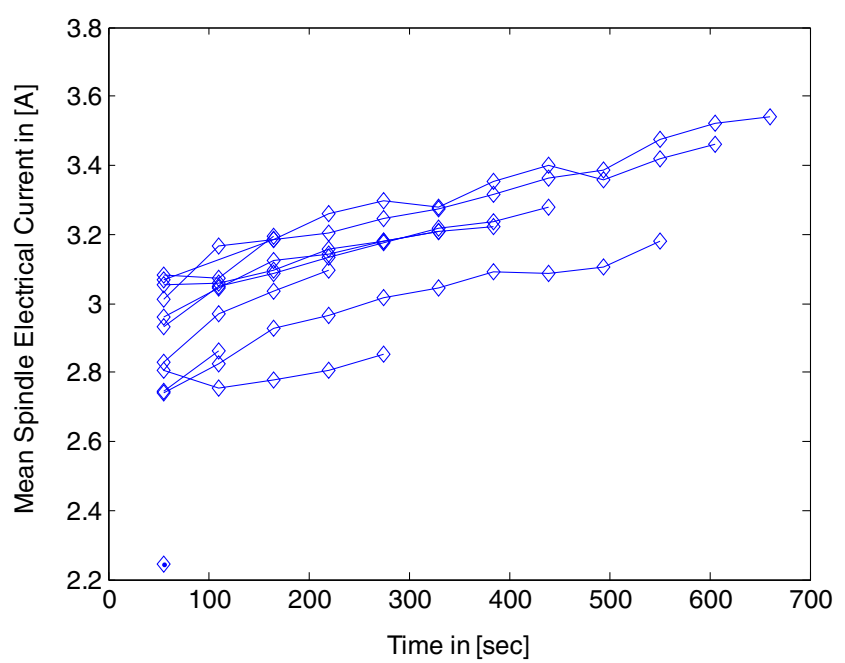

Fig. 10 Spindle current signals at $3000 \mathrm{rpm}$

However, the scattering of the points, as displayed in (Figs 18 and 19) have restricted the acquirement of any algebraic relation. This is due to the statistical nature of measurements. Thus, as an immediate conclusion, it can be stated that when Hol is considered incrementally, referring to the same insert as in [31], it is a good indicator of tool wear; however, statistically, it is very sensitive to the statistical motion profile, owing to the surface roughness. As shown further below in the fused sensor data, the mean power of acceleration is more robust.

The position of the two greatest spectrum maxima (f1, f2) in the arbitrary region $[0,280] \mathrm{Hz}$ and their correlation with the level of tool wear are depicted in Figs. 20 and 21. The particular region has been selected due to its smoothness and easiness of finding specific maxima, aiming at the creation of a library, capable of providing the tool wear level that has given these maxima. This analysis can be considered being a pattern recognition system. Since the various points are

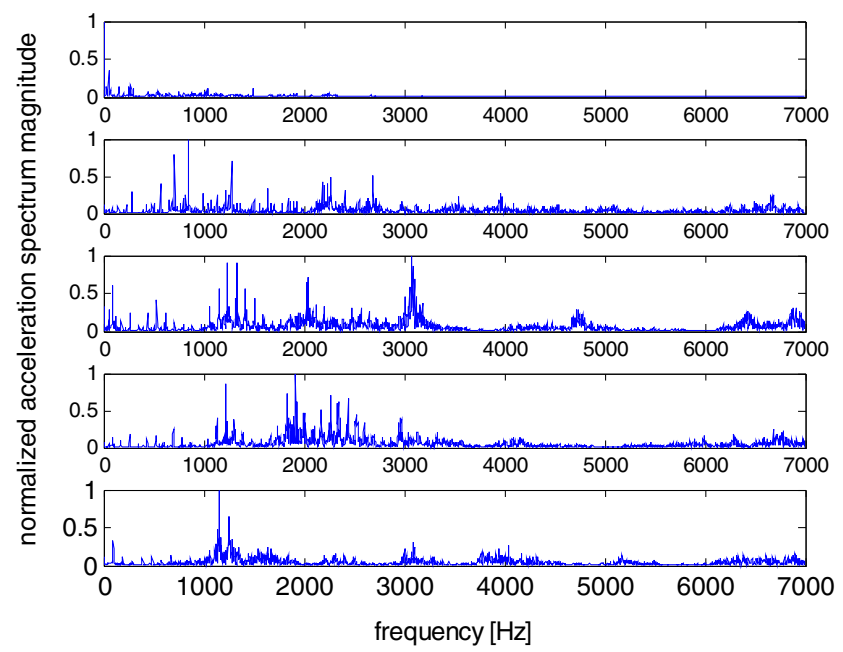

Fig. 11 Evolution of the obtained acceleration signals' spectrum magnitude at $3000 \mathrm{rpm}$

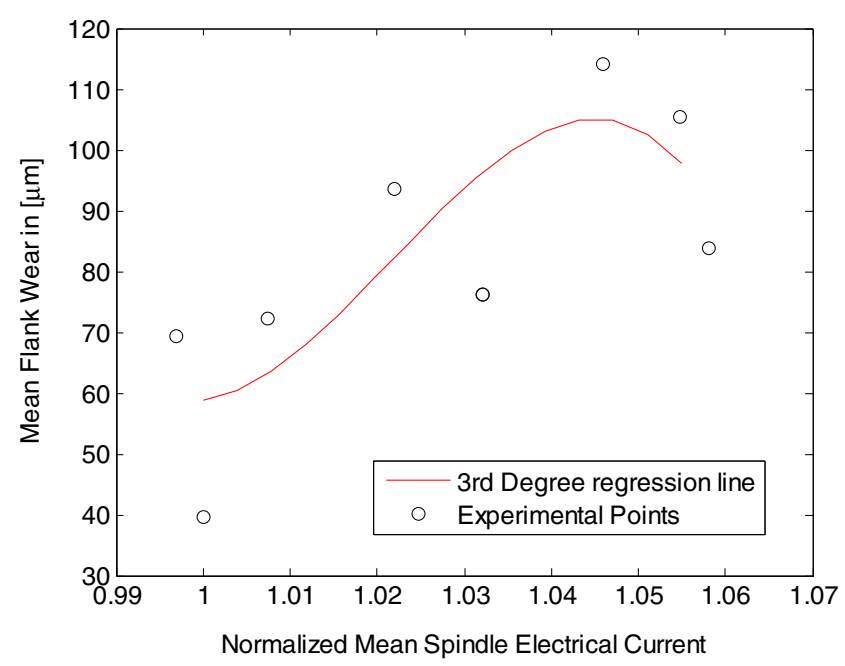

Fig. 12 Correlation between spindle current and tool wear for $1350 \mathrm{rpm}$

relatively separable, the creation of the aforementioned library is feasible.

Finally, a pattern recognition system, based on fused sensors data, has been set up to predict the tool wear level. It has been a single-layer linear, in contrast to [42], the perceptron system (Fig. 22), using both acceleration and current as inputs, with an output was set to provide information on the tool wear level (high, medium, low) compared to that of specific thresholds. Results of this classification are shown in Figs. 23 and 24. Specifically, a set of linear systems has been used for the identification of various tool wear levels. Three fuzzy sets representing tool wear level classes have been used in this study (low (L), medium (M), and high $(\mathrm{H})$ ). The mean value across RPMs of the tool wear thresholds, where this happens has been used as the critical values among $\mathrm{L}, \mathrm{M}$, and $\mathrm{H}$. Two lines in each case, also depicted in the figures below, indicate the thresholds between the various fuzzy tool wear sets.

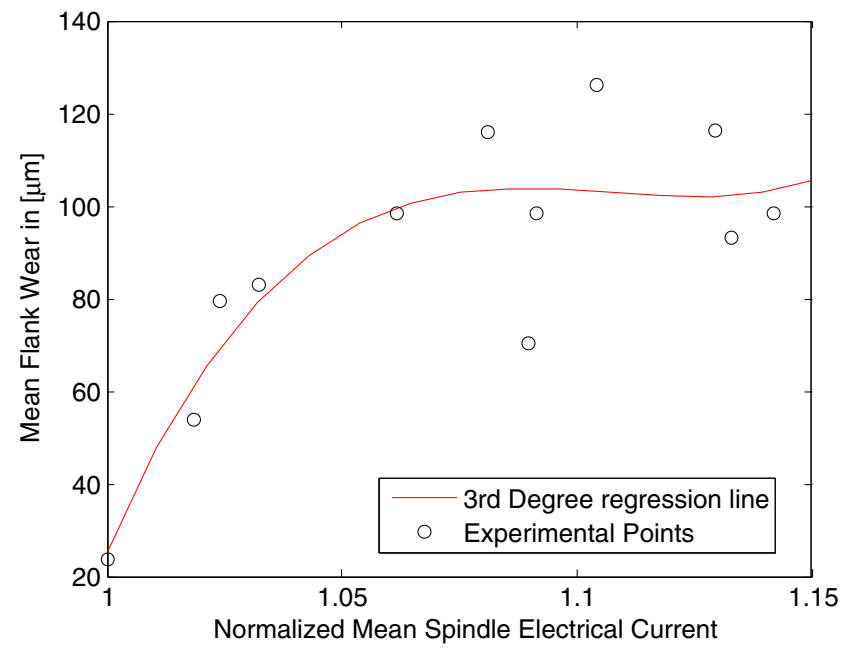

Fig. 13 Correlation between spindle current and tool wear for $2175 \mathrm{rpm}$ 


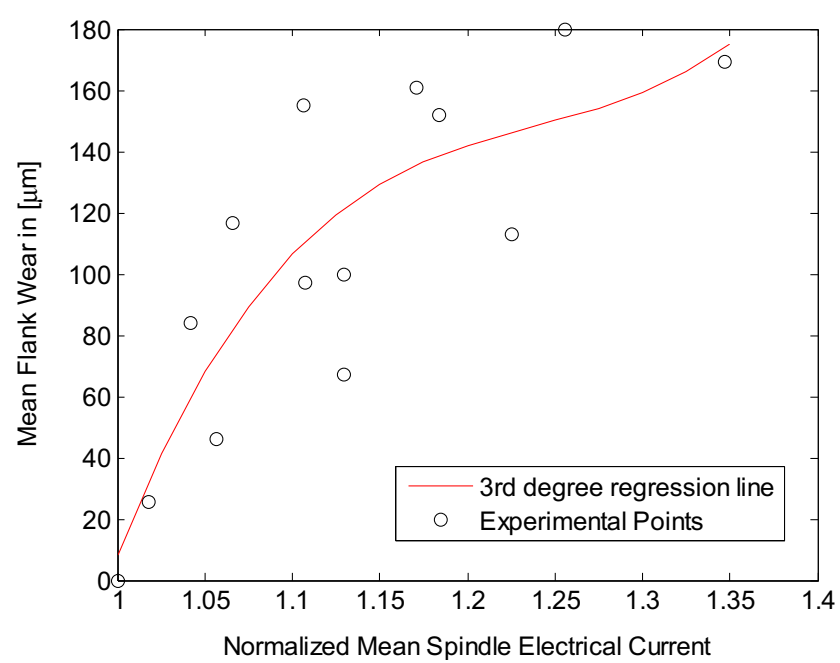

Fig. 14 Correlation between spindle current and tool wear for $3000 \mathrm{rpm}$

Having these lines as decision thresholds would cause a $\operatorname{cost} C$, in case that some points would be misclassified by the perceptron system. This cost can be computed, given that there are four potential events:

1. A: Changing tool

2. B: Not changing tool

3. H: High tool wear level

4. M: Medium tool wear level

and denoting simple costs as follows:

1. $\mathrm{C}_{1}$ : The cost of changing tool

2. $\mathrm{C}_{2}$ : The cost of throwing away the workpiece

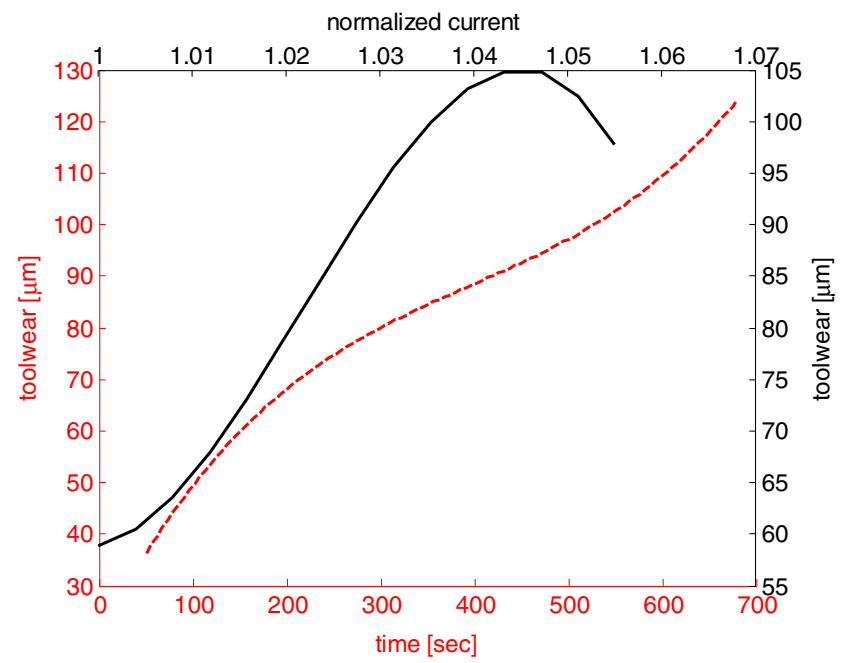

Fig. 15 Tool wear versus time (red line/axis) and electrical current (black line/axis) for $1350 \mathrm{RPM}$

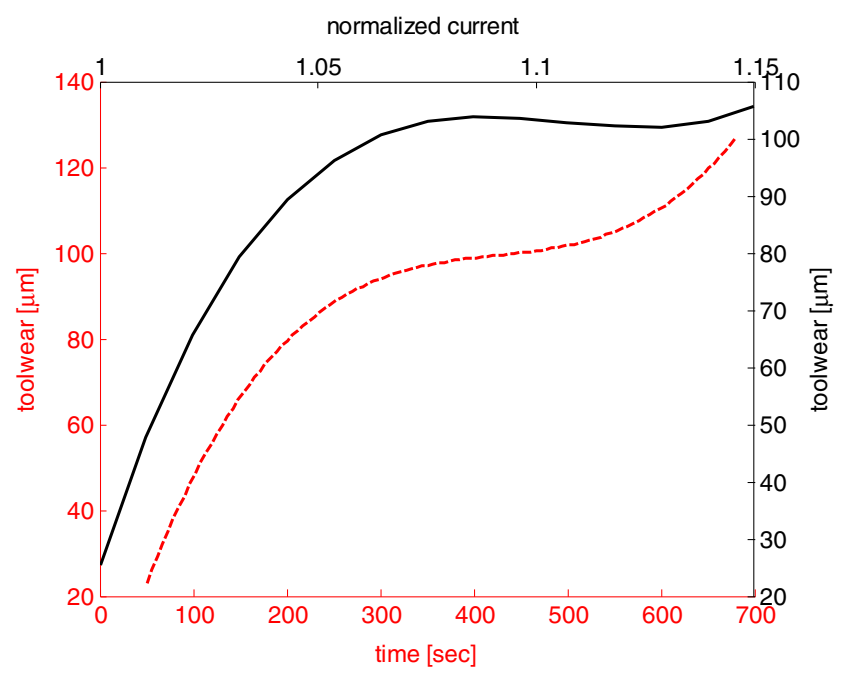

Fig. 16 Tool wear versus time (red line/axis) and electrical current (black line/axis) for 2175 RPM

Following the definition of the corresponding probabilities below (given the shapes used to denoting classified measurements in Fig. 23):

$\left.P_{A}\right|_{M}=\frac{\text { Number of triangles crossing the threshold }}{\text { Total number of triangles }}$

$P_{B \mid L}=\frac{\text { Number of circles crossing the threshold }}{\text { Total number of circles }}$

the cost is calculated to be equal to

$C=P_{A \mid M} C_{B}+P_{B \mid L} C_{2}$

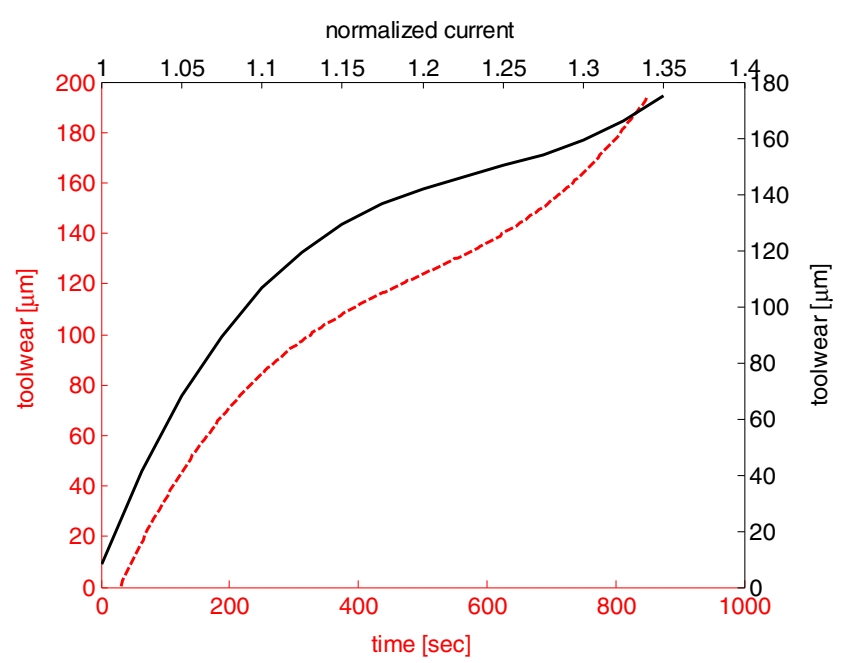

Fig. 17 Tool wear versus time (red line/axis) and electrical current (black linelaxis) for $3000 \mathrm{PM}$ 


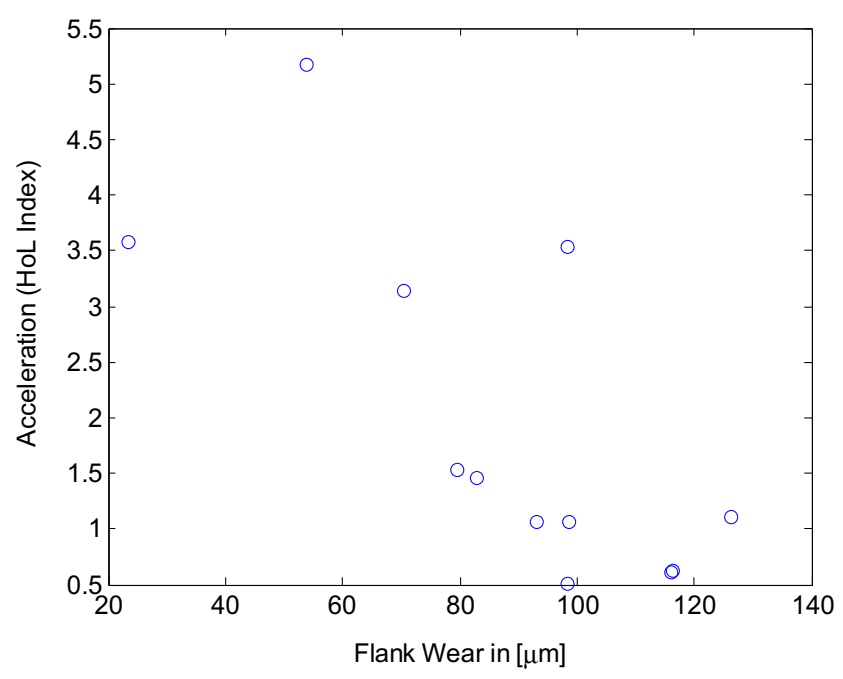

Fig. 18 Accelerometer signals $\mathrm{HoL}$ value against corresponding tool wear (2175 rpm)

From the results, it is clear that the low tool wear level is hard to be made distinct in the case of 3000 RPMs due to the noise existence in both the current and the acceleration signals. The same occurs for the 1175 RPMs. However, in the case of 2175 RPMs, the trend indicated that the high level of tool wear existed for high values of current and low acceleration RMS values. Moreover, since the predictability is cutting speed dependent, it is of interest to compare the predictability measures with those of the machine tool dynamics and consequently, with the nature of the captured signals. The schematic in Fig. 25 provides a graphic overview of the operational analysis (OMA) [56] that has been taken into consideration. The response of the machine tool in the present study has been acquired only by using the result (vibration) during machining, as the machine tool has not be found to be linear in the

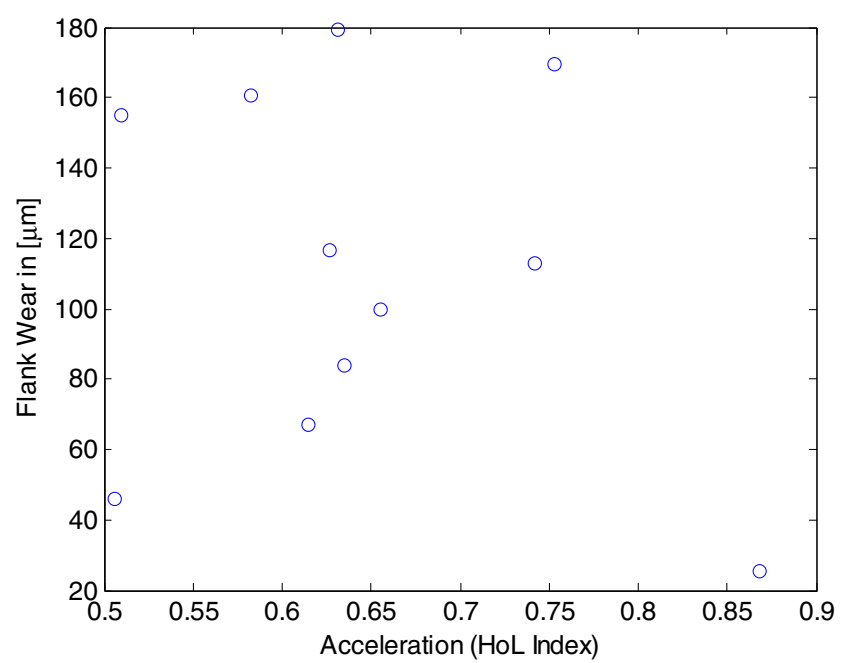

Fig. 19 Accelerometer signals $\mathrm{HoL}$ value against corresponding tool wear (3000 rpm)

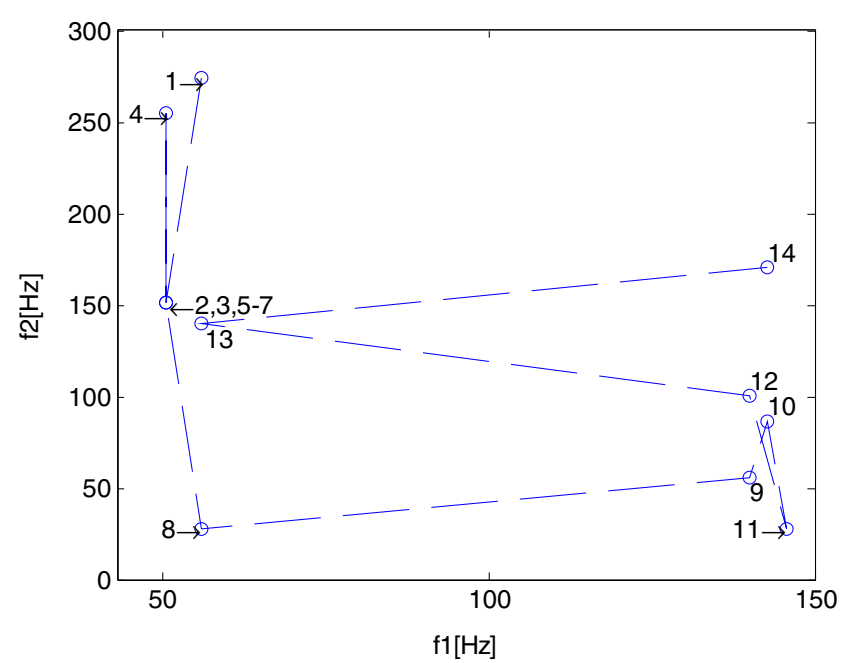

Fig. 20 f1-f2 phase space (2175 rpm)

strict sense via a piezoelectric hammer. Moreover, the spectrum of the excitation; a combination of cutting forces and vibrations due to the rotating spindle, could not be predicted/ estimated.

Figure 26 shows the correlation between the various predictability measures taken into account $(a, b, d)$ and the mean size of vibration (c), given by the RMS acceleration. The horizontal axes are indicative of the cutting speed (in terms of spindle rotational velocity) and the various metrics, normalized with respect to the maximum values, which are depicted in the vertical axes. The residues of the regression in the Figs. 12, 13, and 14 are measured by the $R^{2}$ index, divided by the mean signal power. This is an indication of the inverse predictability of the measurements. An additional predictability metric is the number of discrete linear thresholds that can be set, as it is depicted in Figs. 23 and 24. Both predictability

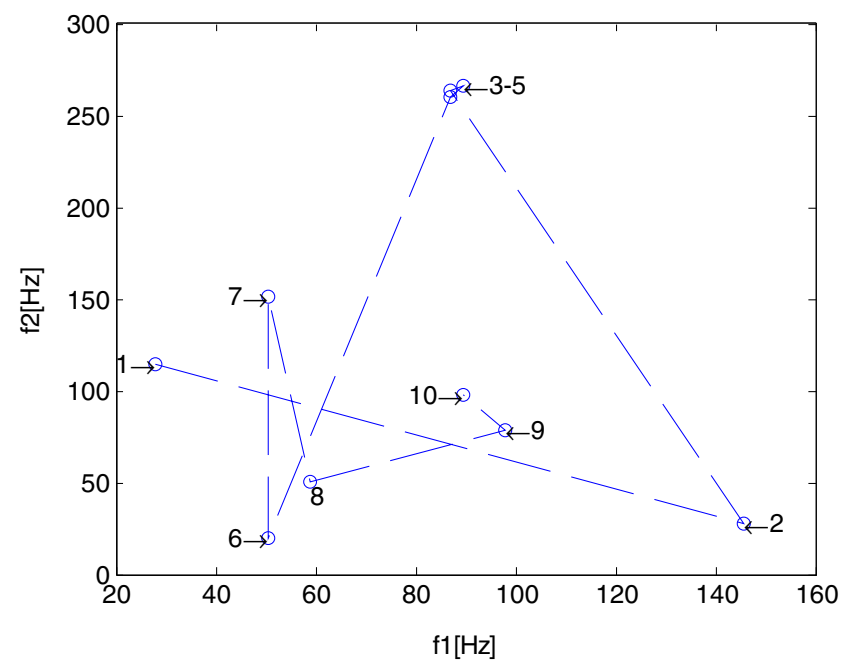

Fig. 21 f1-f2 phase space (3000 rpm) 
Fig. 22 Input/output model of the perceptron pattern recognition system

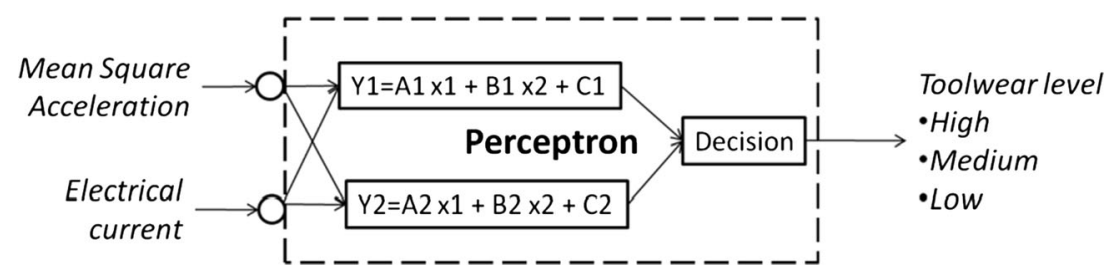

metrics obtain high values at $2175 \mathrm{rpm}$ and low values at $3000 \mathrm{rpm}$. This is also valid in the case of the obtained signal energy levels (Fig. 26c). Finally, regarding the plane $f_{1}-f_{2}$ predicting tool wear, as shown in Figs 20 and 21, the distance between the various points can be considered as an index of predictability. The metric $D_{m}$, which is defined as the maximum distance over the mean distance between the points, has been regarded. Since the values obtained are greater than one, the normalized value from Eq. 4:

$D_{m}^{\prime}=1 /\left(\ln D_{m}+1\right)$

From the diagrams below, it can be seen that when the machine vibrations are intense, due to different machining conditions, the predictability of the tool wear is enhanced.

This trend has to be further compared with the machine's behavior. A modal analysis, however, reveals a nonlinear behavior of the machine, even below $1000 \mathrm{~Hz}$. The transfer function, with force as input and displacement as output, has been considered. Even though the maxima seem to occur in the same frequencies for different forces, the transfer functions are not the same. Furthermore, the fact that the spindle is raised or lowered brings about changes in the transfer function. Therefore, continuing with performing an operational analysis on the machine, simply by rotating the spindle but without cutting, it is found that the minimum energy in displacement is around 2175 RPM, while the displacement

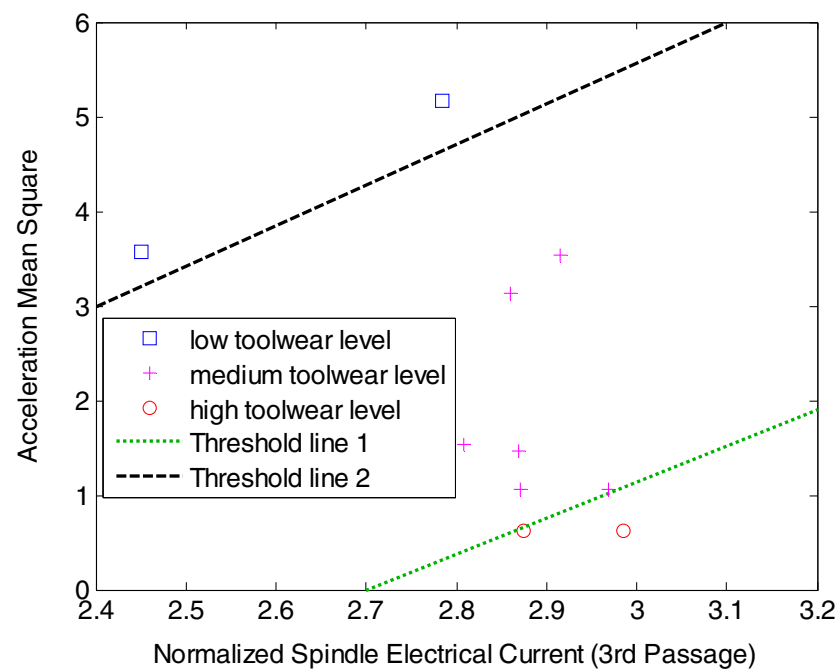

Fig. 23 Classification of tool wear level based on acceleration and spindle current (2175 rpm) energy values are much greater at the remaining RPM values. The load (cutting) changes this trend as seen in the acceleration trend of Fig. 26c. It is indicated that the intensity of oscillation affects the predictability of tool wear in an unobvious way (intensively and inversely proportionally). This dictates that a study be conducted in an ideal situation, where there is no statistical noise on the measurement. The effect of the parameters, in Fig. 25, will then be taken into consideration.

\section{Conclusions}

Multiple sensor monitoring for the tool wear state has been carried out on milling CGI 450 plates through the simultaneous detection of acceleration and spindle drive current sensor signals. Tool wear prediction has been accomplished by utilizing third degree regression models and pattern recognition systems. The electrical current signals provide clearer prediction results since statistically their correlation to tool wear is more immune to ambient noise when compared with the correlation of the tool wear and acceleration metrics. Moreover, sourcing from the current study, the electrical current signal has been proven easier to process, since it consists of simple values with minor fluctuations. When considering the sensor fixturing, the electrical current signal retrieval poses an additional advantage. As far as the fused sensor

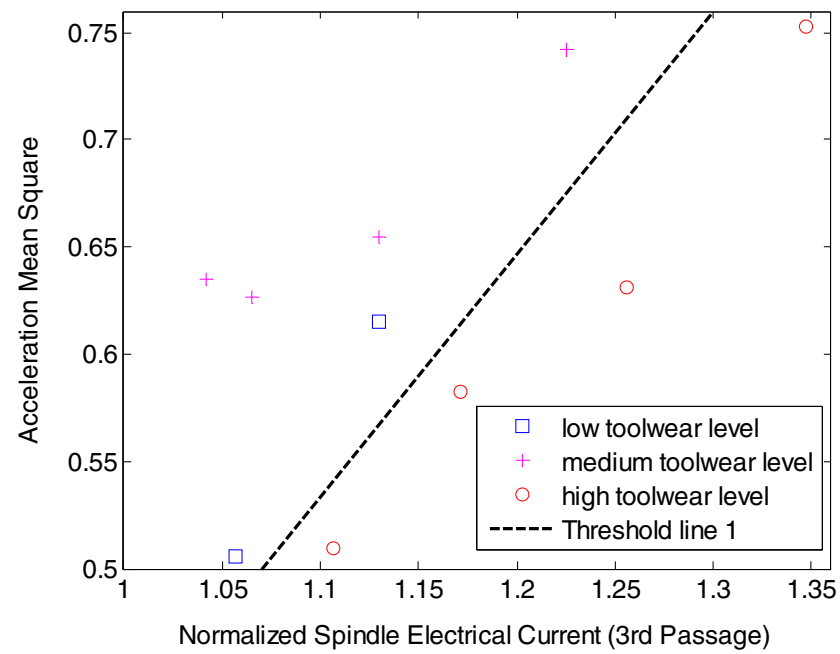

Fig. 24 Classification of tool wear level based on acceleration and spindle current (3000 rpm) 
Fig. 25 Input/output model of a machine according to operational analysis

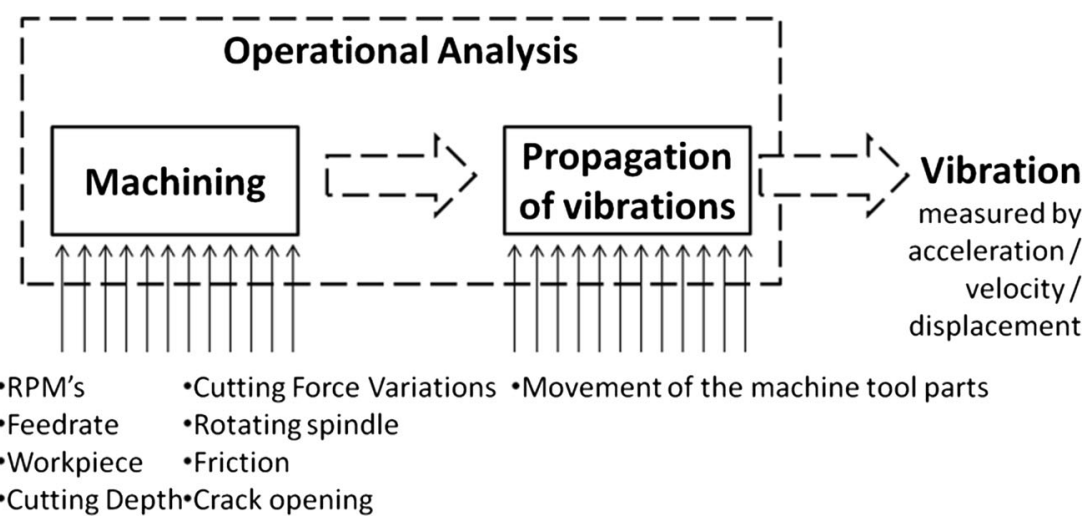

methodology is concerned, it is suggested that the monetary costs due to misclassifying a tool wear measurement be encapsulated in terms of weights in the criterion for setting the threshold in pattern recognition systems.

Regarding a rough quantification of the physical mechanism, according to which the tool-wear-related information is concealed within the acquired signals, there are specific conclusions that can be extracted. Since the cutting force is directly affected by tool wear, the spindle requires more current in order for the milling process to be performed. Furthermore, the change in the vibration of the machine tool is a critical point, as it seems to be the main reason that the vibration signals change when the toolwear levels increase. However, it is up to the studies to investigate into the way that pure information can be extracted, by removing noise related to friction, machine tool components dynamics, and more.

The predictability of the tool wear in a system that uses fused multisensorial data has been also investigated. The derived results indicate that predictability is affected by the mean signal energy, acquired from the vibration acceleration signals. An implication of that is that maximizing both predictability and quality are contradictive optimization objectives. Further research aims to separate the ambient noise and the useful information from the acquired signals using numerical models, along with a stricter formulation of the relationship between the information and the system's predictability.
Fig. 26 Comparison between predictability of tool wear $(\mathbf{a}, \mathbf{b}$, d) and captured acceleration signal energy (c)
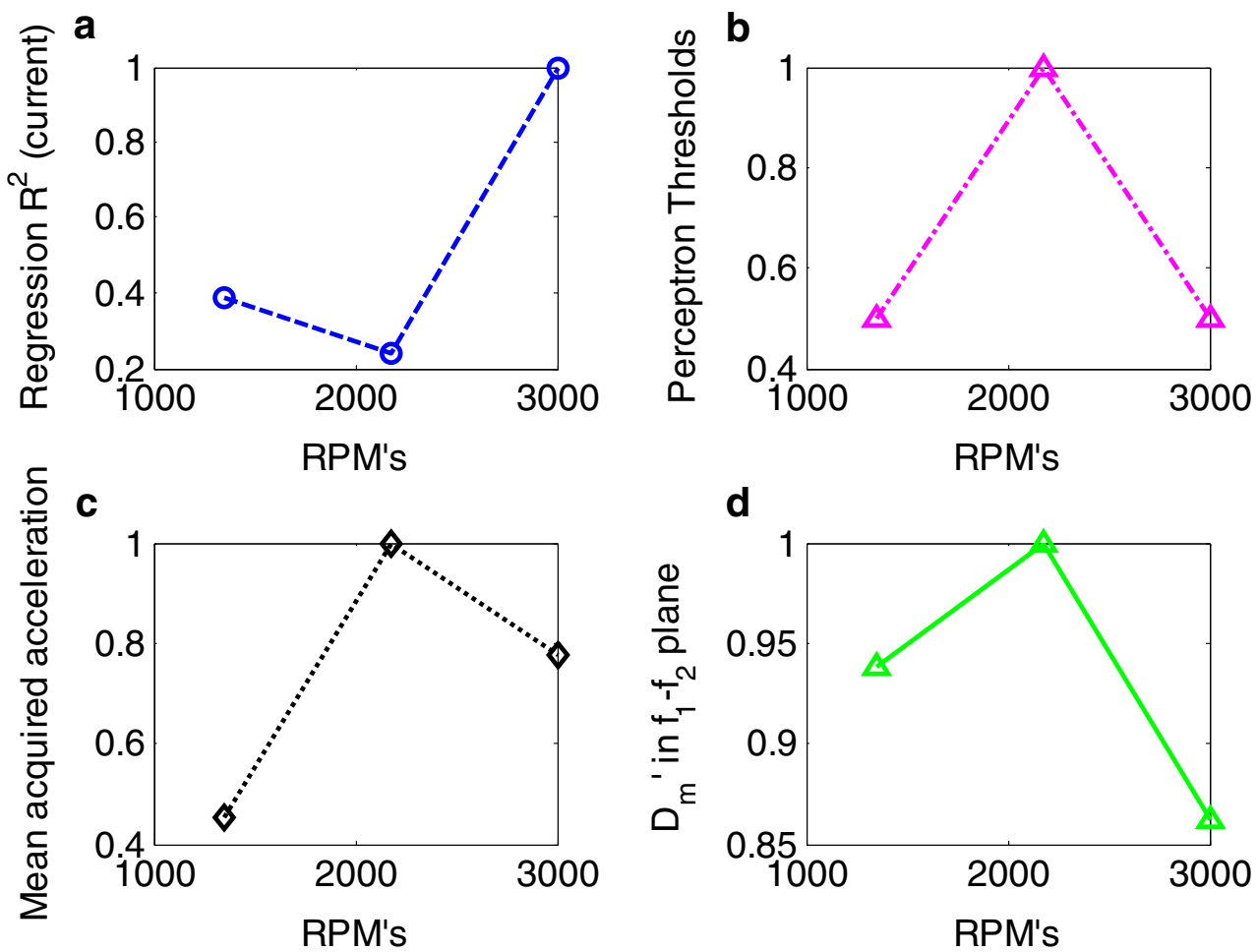
Acknowledgments The work reported in this paper was partially supported by CEC/FP7 NMP-ICT Programme, "The Foundation for the Smart Factory of the Future-FoFdation" (FP7-2010-NMP-ICT-FoF260137).

Open Access This article is distributed under the terms of the Creative Commons Attribution 4.0 International License (http:// creativecommons.org/licenses/by/4.0/), which permits unrestricted use, distribution, and reproduction in any medium, provided you give appropriate credit to the original author(s) and the source, provide a link to the Creative Commons license, and indicate if changes were made.

\section{References}

1. Chryssolouris G (2006) Manufacturing systems - theory and practice, 2nd edn. Springer, New York

2. Ji C, Liu Z, Ai X (2014) Effect of cutter geometric configuration on aerodynamic noise generation in face milling cutters. Appl Acoust 75:43-51

3. Larreina J., Gontarz A., Giannoulis C., Nguyen V.K., Stavropoulos P., Sinceri B. (2013) Smart Manufacturing Execution System (SMES): The possibilities of evaluating the sustainability of a production process, (GCSM) 11th Global Conference on Sustainable Manufacturing, 23-25 September, Berlin, Germany, pp.517-522

4. Wright P.K., Trent E.M. (1974) Metallurgical appraisal of wear mechanisms and processes on high-speed-steel cutting tools, Metals Technology, January 13-23

5. Tarasov SY, Rubtsov VE, Kolubaeva EA (2014) A proposed diffusion-controlled wear mechanism of alloy steel friction stir welding (FSW) tools used on an aluminum alloy. Wear 318(1-2): 130-134

6. Jantunen E (2002) A summary of methods applied to tool condition monitoring in drilling. Int J Mach Tools Manufac 42:997-1010

7. Salonitis K, Kolios A (2014) Reliability assessment of cutting tool life based on surrogate approximation methods. Int J Adv Manuf Technol 71(5-8):1197-1208

8. Li H, He G, Qin X, Wang G, Lu C, Gui L (2014) Tool wear and hole quality investigation in dry helical milling of Ti-6Al-4V alloy. Int J Adv Manuf Technol 71:1511-152

9. Lim G (1995) Tool-wear monitoring in machine turning. J Mat Process Technol 51:25-36

10. Smith GT (1989) Advanced machining, IFS Publications. Springer, UK

11. Wang W. H., Hong G. S., Wong Y. S. and Zhu K. P. (2007) Sensor fusion for online tool condition monitoring in milling, Vol. 45, No. 21, 1 November, 5095-5116

12. Stavropoulos P, Stournaras A, Chryssolouris G (2009) On the design of a monitoring system for desktop micro-milling machines. Int J Nanomanufac 3(1/2):29-39

13. Kavaratzis Y, Maiden JD (1989) System for real time process monitoring and adaptive control during CNC deep hole drilling, in: proceedings of Comadem '89. Kogan Page, London, pp 148-152

14. Jantunen E. (2002) A solution for tool wear diagnosis, in: proceedings, International Journal of Machine Tools \& Manufacture 42, 997-1010, 1999, pp. 95-104

15. Li X (1999) On-line detection of the breakage of small diameter drills using current signature wavelet transform. Int J Mach Tools Manufac 39(1):157-164

16. Lee DE, Hwang I, Valente CMO, Oliveira JFG, Dornfeld DA (2006) Precision manufacturing process monitoring with acoustic emission. Int J Mach Tools Manufac 46:176-188
17. Jemielniak K, Arrazola PJ (2008) Application of AE and cutting force signals in tool condition monitoring in micro-milling. CIRP J Manuf Sci Technol 1:97-102

18. Cao H, Chena X, Zia Y (2008) End milling tool breakage detection using lifting scheme and Mahalanobis distance. Int J Mach Tools Manufac 48:141-151

19. Chryssolouris G., Guillot M., Domroese M. (1987) Tool wear estimation for intelligent machining, symposium on intelligent control, ASME Winter Annual Meeting, Boston, Massachusetts, pp. 35-43

20. Principe C, Yoon T (1991) A new algorithm for the detection of tool breakage in milling. Int J Mach Tools Manufac 31:443-454

21. Stavropoulos P., Salonitis K., Stournaras A., Pandremenos J., Paralikas J., Chryssolouris G. (2007) Experimental investigation of micro-milling process quality, 40th CIRP International Seminar on Manufacturing Systems, Liverpool

22. Ertekin YM, Kwon Y, Tseng B (2003) Identification of common sensory features for the control of CNC milling operations under varying cutting conditions. Int J Mach Tools Manufac 43:897-904

23. Stavropoulos P., Salonitis K., Stournaras A., Pandremenos J., Paralikas J., Chryssolouris G. (2007), Advances and challenges for tool condition monitoring in micro-milling, IFAC Workshop on Manufacturing Modelling, Management and Control, pp. 157162

24. Kluft, W. (1983) Werkzeuguberwachungssysteme furs die Drehbearbeitung, doctoral thesis, RWTH Aachen

25. Prickett PW, Johns C (1999) An overview of approaches to end milling tool monitoring. Int J Mach Tools Manuf 39:105-122

26. Ritou M, Garniera S, Fureta B, Hascoet JY (2014) Angular approach combined to mechanical model for tool breakage detection by eddy current sensors. Mech Syst Signal Process 44(1-2):211220

27. Chryssolouris G., Domroese M. (1988) Sensor integration for tool wear estimation in machining, symposium on sensors and controls for manufacturing, ASME Winter Annual Meeting, Chicago, Illinois, USA, pp. 115-123

28. Chryssolouris G(1982) Effects of machine-tool-workpiece stiffness on the wear behavior of superhard cutting materials. CIRP Ann 31(1):65-69

29. Segreto T., Simeone A., Teti R. (2013) Multiple sensor monitoring in nickel alloy turning for tool wear assessment via sensor fusion, Procedia CIRP 12, 85-90, 8th CIRP Conference on Intelligent Computation in Manufacturing Engineering

30. Ee KC, Li PX, Balaji AK, Jawahir IS, Stevenson R (2006) Performance-based predictive models and optimization methods for turning operations and applications: part 1-tool wear/tool life in turning with coated grooved tools. J Manuf Process 8(1):54-66

31. Doukas C., Stavropoulos P., Papacharalampopoulos A., Foteinopoulos P., Vasiliadis E., Chryssolouris G. (2013) "On the estimation of tool-wear for milling operations based on multisensorial data", (CIRP CMMO) Procedia CIRP, 14th CIRP Conference on Modelling of Machining Operations, 13-14 June, Turin, Italy

32. Segreto, T., Teti R. (2008) "Sensor fusion of acoustic emission and cutting force for tool wear monitoring during composite materials machining", 6th CIRP International Conference on Intelligent Computation in Manufacturing Engineering-CIRP ICME'08, 23-25 July 2008, Naples, Italy, p. 221

33. Segreto T, Simeone A, Teti R (2012) "Sensor fusion for tool state classification in nickel superalloy high performance cutting", 5th CIRP international conference on high performance cutting. Procedia CIRP 1:593

34. Balakrishnan, P., Trabelsy, H., Kannatey-Asibu, E., Emel, E. A. (1989) "Sensor fusion approach to cutting tool monitoring", Proc. 15th NSF Conf. on Production Research and Technology, SME, University of California, Berkeley, p. 101 
35. Chiu, S.L., Morley, D.J., Martin, J. (1987) “Sensor data fusion on a parallel processor", Proc. IEEE Int. Conf. on Robotics and Automation, Raleigh, NC, p. 1629

36. Rangwala S, Dornfeld DA (1987) "Integration of sensors via neural networks for detection of tool wear states". Proc Winter Ann Meet ASME, PED 25:109

37. Santochi M, Dini G, Tantussi G (1997) A sensor-integrated tool for cutting force monitoring. CIRP Ann 46/1:49

38. Ghosh N, Ravi YB, Patra A, Mukhopadhyay S, Paul S, Mohanty AR, Chattopadhyay AB (2007) Estimation of tool wear during CNC milling using neural network-based sensor fusion. Mech Syst Signal Process 21:466-479

39. Von Nedeß C., T. Himburg (1986) Automatisierte Uberwachung des Bohrens, VDI-Z, Bd 128 (17), 651-657

40. Tansel IN, Mekdeci C, Rodriguez O, Uragun B (1993) Monitoring drill conditions with wavelet based encoding and neural network. Int J Mach Tools Manufac 33(4):559-575

41. Ertunc H. M., Loparo K.A., Ocak H. (2001) Tool wear condition monitoring in drilling operations using hidden Markov models (HMMs), Int J Mach Tools Manufac 411363-1384

42. Rao KV, Murthy BSN, Rao NM (2014) Prediction of cutting tool wear, surface roughness and vibration of work piece in boring of AISI 316 steel with artificial neural network. Measurement 51:6370

43. Roth J. T., Pandit S. M. (1999) Monitoring end-mill wear and predicting tool failure using accelerometers. J Manufac Sci Eng Volume 121, Issue 4

44. Čuš F, Župerl U (2011) Real-time cutting tool condition monitoring in milling. Strojniški vestnik - J Mech Eng 57(2):142-150

45. Zheng G., Zhao J., Li Z., Cheng X., Li L.(2014) Fractal characterization of the friction forces of a graded ceramic tool material

46. Wang GF, Yang YW, Zhang YC, Xie QL (2014) Vibration sensor based tool condition monitoring using support vector machine and locality preserving projection. Sensors Actuators A 209:24-32
47. FoFdation Deliverable 4.2 (May 2013) An intelligent adaptive \& sustainable approach, ARTIS

48. Tansel IN, Arkan TT, Bao WY, Mahendrakar N, Shisler B, Smith D, McCool M (2000) Tool wear estimation in micro-machining. part I: tool usage-cutting force relationship. Int J Mach Tools Manufac 40: 599-608

49. Chakraborty P, Asfour S, Cho S, Onar A, Lynn M (2008) Modeling tool wear progression by using mixed effects modeling technique when end-milling AISI 4340 steel. J Mater Process Technol 205: 190-202

50. Da Silva MB, Naves VTG, De Melo JDB, De Andrade CLF, Guesser WL (2011) Analysis of wear of cemented carbide cutting tools during milling operation of gray iron and compacted graphite iron. Wear 271:2426-2432

51. http://www.google.com/patents/US6638609, retrieved July 15, 2014

52. Kalpajian S (1996) Manufacturing processes for engineering materials, 3rd edn. Addison-Wesley, Longman

53. Papacharalampopoulos A, Stavropoulos P, Doukas C, Foteinopoulos P, Chryssolouris G (2013) Acoustic emission signal through turning tools: a computational study. Procedia CIRP 8(2013):426-431

54. P Fromme1 and C Rouge (2011) Directivity of guided ultrasonic wave scattering at notches and cracks, Journal of Physics: Conference Series 269012018

55. MatWeb's searchable database of material properties, http://www. matweb.com/index.aspx

56. Li B, Cai H, Mao X, Huang J, Luo B (2013) Estimation of CNC machine-tool dynamic parameters based on random cutting excitation through operational modal analysis. Int J Mach Tools Manufac $71: 26-40$ 